\title{
A EXPERIÊNCIA DA IMAGEM EM INSTALAÇÕES INTERATIVAS
}

\author{
La experiencia de la imagen en instalaciones interactivas \\ Image experience in interactive installations
}

Andreia Machado Oliveira ${ }^{1}$

\begin{abstract}
Resumo
Trazemos, nesse artigo, uma concepção de imagem atrelada à experiência corporal a partir de produções em Arte Interativa. Buscamos um conceito de imagem não voltado a uma representação já individuada, mas sim que considere o processo de geração da própria imagem. Para Gilbert Simondon, a imagem é concebida como um ciclo dentro de uma abordagem sistêmica e processual da realidade. Nesse sentido, encontramos ressonâncias entre essa concepção de imagem e as produções de instalações interativas no Lablnter, em especial nas obras coletivas: “EntreMeios" (2015), "Permanência do Gesto" (2017) e "Ambulações" (2017).
\end{abstract}

Palavras-chave: Imagem; Arte interativa; Instalações; Lablnter; Gilbert Simondon

\section{Resumen}

Traemos, en ese artículo, una concepción de imagen ligada a la experiencia corporal a partir de producciones en Arte Interactivo. Buscamos un concepto de imagen no orientado a una representación ya individuada, sino que considere el proceso de generación de la propia imagen. Para Gilbert Simondon, la imagen se concibe como un ciclo dentro de un enfoque sistémico y procesal de la realidad. Encontramos resonancias entre esa concepción de imagen y las producciones del Lablnter en instalaciones interactivas, en especial en las obras colectivas: “Entremedios” (2015), “Permanencia del Gesto" (2017) y “Ambulaciones” (2017).

Palabras-clave: Imagen; Arte interactivo; Instalaciones; LabInter; Gilbert Simondon

\begin{abstract}
In this article, we draw a conception of image linked to the corporal experience from productions in Interactive Art. We seek a concept of an image that is not directed towards an already individuated representation, but rather that considers the process of generating the image itself. For Gilbert Simondon, the image is conceived as a cycle within a systemic and procedural approach to reality. We find resonances between this conception of image and the productions of Lablnter in Interactive Art, especially in collective artworks: "Between Milieaus" (2015), "Permanence of Gesture" (2017) and "Walkness" (2017).
\end{abstract}

Keywords: Image. Interactive art; Installations; LabInter; Gilbert Simondon

1 - Artista multimídia e professora do Departamento de Artes Visuais e do Programa de Pós-graduação em Artes Visuais da UFSM. Coordenadora do LabInter (Laboratório Interdisciplinar Interativo) - UFSM e líder do gpc.InterArtec/Cnpq, desde 2012. Doutora em Informática na Educação pela UFRGS - Brasil e pela Université de Montreal/UdM - Canadá, Mestre em Psicologia Social e Institucional pela UFRGS e Graduada em Bacharelado e Licenciatura em Artes Visuais pela UFRGS, e-mail: andreiaoliveira.br@gmail.com 
Falamos, na atualidade, em territórios informacionais, cibercidades, ciberespaço, telemática, ciborgue, realidade mista, realidade aumentada, terminologias que nos levam a pensar nossa existência de uma forma expandida e híbrida, não comportando mais concepções espaço-temporais exclusivamente antropocêntricas, físicas e mensuráveis em sistemas fechados (OLIVEIRA, 2015).

Tais terminologias evidenciam realidades que não comportam mais polarizações entre natural e artificial, humano e máquina, ao contrário, nos provocam e inquirem a revisão de vários aspectos do que chamamos realidade, dentre eles a noção que temos de imagem. Buscamos uma concepção de imagem sistêmica e processual que encontra sustentação teórica em Gilbert Simondon (2008), com sua abordagem cíclica da imagem.

Nesse sentido, encontramos ressonâncias entre essa concepção de imagem e as produções de instalações interativas no Lablnter², em especial nas obras coletivas: "EntreMeios" (2015), "Permanência do Gesto" (2017) e "Ambulações" (2017).

\section{A Imagem em Gilbert Simondon ${ }^{3}$}

Entendemos a imagem não como um termo dado a ser analisado, já individuado, contudo em seu processo de individuação, em sua gênese. Simondon (2008) constrói uma concepção de imagem a partir de sua compreensão sobre o processo de individuação, ou seja, a imagem é concebida dentro de uma abordagem sistêmica e processual da realidade. Neste sentido, o ciclo da gênese da imagem é formado por quatro fases em constante transformação: imagem-motora, imagem-percepção, imagem-mental e imagem-invenção.

Com a imagem-motora estão criadas as condições motoras para uma posterior adaptação ao meio. Por isso, é a imagem que faz com que o objeto surja para o sujeito, ela precede o próprio objeto. O movimento motor precede a percepção sensorial, de modo que para o estímulo/resposta ocorrer, em relação a determinado meio, é necessário um elevado nível de organização para a recepção destes sinais. A partir de um efeito constante da atividade motora, a imagem cria uma situação a priori para uma identificação perceptiva futura do objeto. É a própria programação genética de um organismo sobre o seu meio (SIMONDON, 2008).

Sobre a imagem-motora, aproximamos questões referentes à Arte e Tecnologia. Tratam-se de propostas artísticas que remetem a relações entre arte, ciência e tecnologia, a estrutura dos corpos, suas ações e conexões. "Arte e natureza têm se mesclado, dobrando-se uma sobre a outra e formando um continuous sensorium" (LATOUR, 2006, p. 107). Na interação com tecnologias emergentes, o corpo expande suas estruturas motoras e funções físicas e mentais, adquire outras maneiras de sentir, perceber, agir e pensar. Sendo visto a partir da era pós-biológica, uma vez que "atualmente o que tem sentido já não é a liberdade de ideias, mas a liberdade de formas: a liberdade de modificar e mudar o corpo. As pessoas montadas por fragmentos - comenta Stelarc - são experiências pós-evolutivas" (GIANETTI, 2006, p. 13). A geração das imagens encontra-se cada vez mais incorporada na estrutura corporal, desde sua fase motora e perceptiva como experiência, sua fase mental como imaginação e símbolo, até sua fase inventiva como objetos tecno-estéticos ou propostas concretizadas.

Atualmente, as tecnologias digitais estão presentes dentro e fora dos corpos em realidades híbridas. Cada tecnologia nova traz implicações aos processos de criação e fruição. A partir das imagens-motoras produzidas pela motricidade, os corpos são capazes de desenvolver sensorialidades em relação ao meio em que se encontram, fazendo surgir a imagem-percepção. A percepção "é um movimento real, porque alguma coisa está acontecendo: o corpo está capacitado. Isto é, tem sido relacionalmente ativado" (MASSUMI, 2002, p. 90). A imagem-percepção permite que da interação do sujeito com o meio externo surja o objeto a partir da experiência presente. Um número de respostas é realizado a partir da ação de sinais e estímulos sobre os vivos e os não-vivos no meio associado.

Imagem-percepção evoca uma ação com o objeto a partir da percepção dos signos do meio. Portanto, o objeto surge e se constrói na experiência, no momento presente, como uma reação aos signos do meio. A percepção não é uma ação do sujeito sobre o meio que contém objetos, todavia, um efeito de relações sistêmicas que incluem sujeitos, objetos e meios sem qualquer hierarquia, "a percepção existe entre quem percebe e o percebido" (MASSUMI, 2002, p. 160). Não é a obra, objeto completo, que mostra algo, ou o sujeito, estruturado, que percebe algo; mas sim a percepção é o que se produz nesse encontro entre obra e sujeito.

Os aparelhos tecnológicos cada vez mais estão alterando nossa percepção sobre o meio, influenciando nos signos contidos nos mesmos, transformando-os, misturando, incorporando através da construção de ambientes virtuais em

2 - O Lablnter é um laboratório de pesquisa e criação nas áreas de arte, ciência e tecnologia. Constituído por uma equipe interdisciplinar que envolve as áreas de arte, design, engenharia, computação, arquitetura, cinema e música, vem desenvolvendo propostas interativas, imersivas e colaborativas, desde 2012 na Universidade Federal de Santa Maria. (labinter.com.br) (https://www.facebook.com/labinterartec/)

3 - Referência ao artigo "Imagem como Objeto Tecno-estético em Arte e Tecnologia" de Andréia Machado Oliveira e Felix Rebolledo, publicado na revista Informática na Educação: teoria e prática, 2018. 
games e caves de realidade aumentada com uso de implantes, óculos, tablets, celulares, etc. Obras de realidade virtual, como "Osmose" (1995) de Charlotte Davies, podem proporcionar uma experiência sem contiguidade com o referente real e com outras situações espaço-temporais.

Enquanto ambientes virtuais anteriores apresentavam portais que resultavam em transições abruptas, no mundo das imagens de Osmose o observador vivencia transições osmóticas de uma esfera a outra, vendo uma esfera esmorecer lentamente antes de se amalgamar à próxima (GRAU, 2007, p. 222).

Em "Osmose", o espectador entra em estado de imersividade nas transformações daquela paisagem digital, experimentando sensações de leveza, falta de gravidade, movimentos multidirecionais. Utiliza-se capacete de realidade virtual, recursos da computação gráfica 3D e sons que são explorados sinestesicamente (OLIVEIRA, 2010).

O artista brasileiro André Parente, na instalação interativa "Figuras na Paisagem" (2005), utiliza um dispositivo imersivo chamado Visorama, que simula um binóculo, com a intenção de mostrar imagens de paisagens digitalizadas de fotografias panorâmicas, vídeos e sons. Diversas imagens e sons são ativados, ao mesmo tempo, permitindo a coexistência de espaços e tempos diversos. Podemos dizer que o Visorama é uma máquina que produz informações nas paisagens, não no sentido de transmitir dados sobre locais conhecidos; mas, que produz deslocamentos no público, ao navegar e compartilhar espaços e tempos simultâneos, sendo disparador para novas individuações (OLIVEIRA, 2010).

Portanto, as imagens que percebemos e registramos em nossa mente, na atualidade, são essencialmente imagens tecnológicas (analógicas e digitais). A imagem-mental surge de um modo análogo com o meio externo. Em seguida, as imagens motoras e perceptivas são mentalmente organizadas e sistematizadas de acordo com uma ressonância afetivo -emocional com o meio externo. Memórias consistem em imagens que foram retidas quando a situação e a experiência já não existem mais (SIMONDON, 2008). Memórias, e posteriormente símbolos, constituem a base imagética para a produção inventiva de objetos-imagens.

A imagem-invenção produz um deslocamento espaço-temporal dentro do meio. Ela está diretamente relacionada com a invenção técnica e estética, onde a imaginação criativa é a capacidade de inventar objetos tecno-estéticos, uma capacidade de lização e comunicação. Na própria produção da imagem, como Simondon coloca, "todos os objetos produzidos pelo homem são objetos-imagens que a imaginação concretiza" (SIMONDON, 2008, p. 13). O objeto é um efeito da atividade da invenção, mas, principalmente, é uma abertura para realidades primitivas imprevistas. "Depois da invenção, quarta fase do devir das imagens, o ciclo recomeça, por uma nova antecipação de reencontrar o objeto, que por ele se produz" (SIMONDON, 2008, p. 3). Neste sentido, Simondon (2008) se refere à gênese da imagem como um ciclo que não se finda em uma fase específica, a imagem-invenção não é a finalização do ciclo, mas apenas uma fase que se relaciona com as demais.

\section{Lablnter e produção de instalações interativas}

Ao pensarmos sobre a imagem-invenção, mencionamos a instalação interativa "EntreMeios" (2015), produzida no Lablnter/UFSM, por Andréia Machado Oliveira, Matheus Camargo Moreno, Marcos Cichelero, Fabio Gomes de Almeida e Evaristo do Nascimento (Figura 1), que explora o ato de habitar e de se mover entre meios distintos. As imagens construídas em espacialidades e temporalidades diversas se hibridizam em um mesmo espaço em tempo real, propiciando interatividade entre a obra e o público. Nesta instalação interativa, coexistem três meios geográficos diferentes sobrepostos em temporalidades distintas. Primeira camada: imagens do meio local de Santa Maria, em um reservatório do tempo passado; segunda camada: s imagens do meio local do Rio de Janeiro, em um tempo presente; terceira camada: imagens do meio local da instalação no evento Hiperorgânicos 5/UFRJ, em espera por atualizações do público em um tempo futuro.

O público torna-se um interator na produção de imagens. As obras interativas se efetuam e se modificam ao longo da experiência artista/espectador/obra/meio, rompendo com a moldura e exigindo participação, já que é, fundamentalmente, relacional.

As obras interativas, ao serem obras de ação, podem produzir ações-reações instantâneas, ou suas ações podem ser efetivações de operações tecno-estéticas da própria obra, realizadas pelos interatores, ou seja, uma obra que mantém abertas suas operações, fazendo com que o próprio interator possa ter acesso às formas implícitas da obra (OLIVEIRA, 2010, p. 21). Na arte interativa, "o observador não se contenta mais em percebê-la à distância; ele interage com ela, comanda-a pelo gesto, pelo olhar ou pela voz; ele não se detém mais na sua superfície, aí mergulha totalmente" (COUCHOT, 2003, p. 267). 
Figura 1 - Andréia Machado Oliveira, Matheus Camargo Moreno, Marcos Cichelero, Fabio Gomes de Almeida e Evaristo do Nascimento (Lablnter), "EntreMeios”, Hiperorgânicos 5, 2015

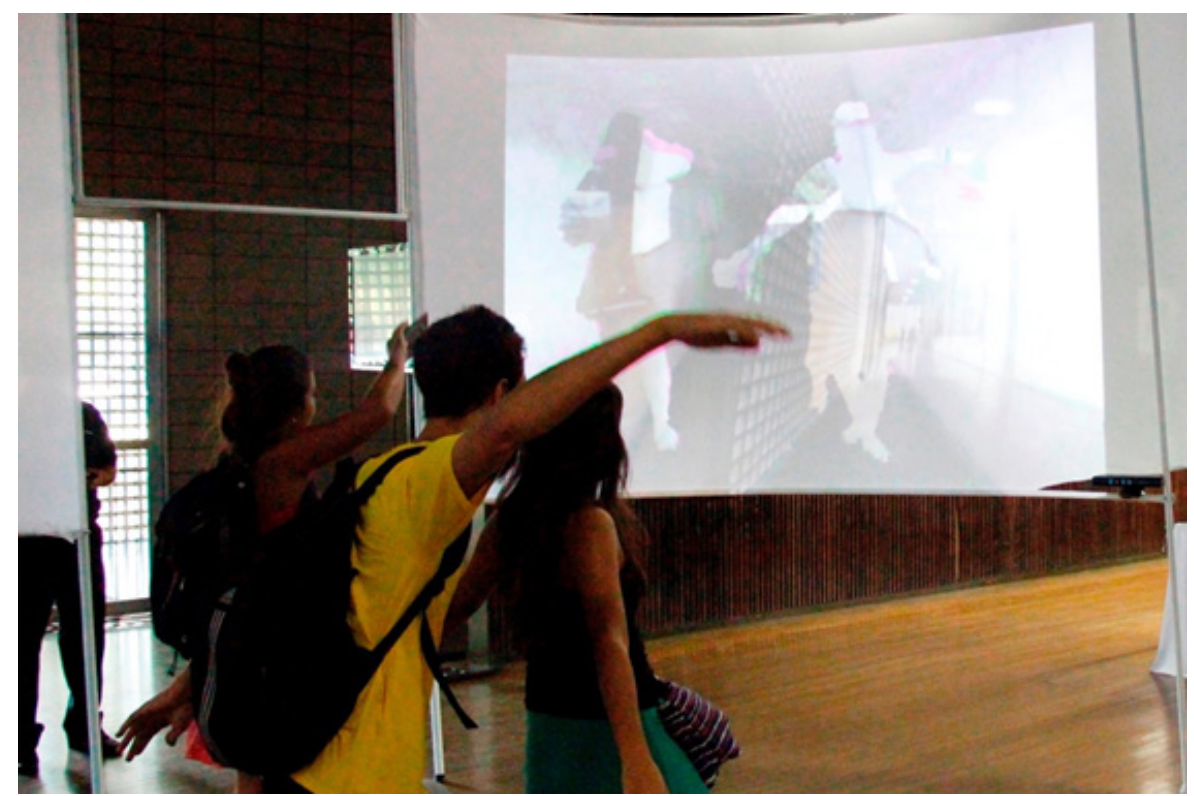

Fonte: Matheus Camargo Moreno (Lablnter)

Nessas relações entre imagens e meios, entendemos que a imagem é a própria experiência, ela se encontra entre o sujeito e o mundo. Uma imagem que se produz dentro e fora do computador, que segundo Couchot:

a imagem numérica faz corpo com o circuito do computador e seus prolongamentos reticulares. Imagem-matriz, quando a definimos na sua morfogênese, imagem-rede, quando se define em seu modo de distribuição, a imagem contém uma infinidade potencial de outras imagens. É uma imagem na potência da imagem (COUCHOT, 2003, p. 267).

Contagiamo-nos pelas imagens em fluxo constante, pelos ritmos dos meios, pelas misturas de elementos humanos e não humanos. São atos de retirar elementos de seu meio correspondente e levá-los para outros meios aonde ganham novas significações nas associações com outros elementos. Em “EntreMeios", o processo de criação se constrói no ato de incorporações híbridas entre diferentes corpos e meios, sendo a imagem uma produção coletiva entre humanos e não-humanos.

Na instalação interativa "Permanência do Gesto"4 (2017) partimos da imagem-motora que guia os gestos à imagem-invenção que concretiza a obra. A memória do gesto é captada por uma câmera termográfica de sensor infravermelho (Flir SC300) que faz perdurar o próprio gesto a partir do delay do software Processing. Ao transpor meios distintos (do analógico ao digital), buscamos levar "a permanência do gesto" registrada na tradição pictórica de modo duradouro para a produção digital contemporânea de modo efêmero. Nesse sentido, pensamos a sustentabilidade do gesto em sua permanecia por determinado tempo, longo ou curto prazo, bem como as maneiras de seu registro e rastro, sua visibilidade e invisibilidade.

Durante o evento de Design+ 2017 (Figura 2), na Universidade Federal de Santa Maria, em um primeiro momento, houve a realização de uma performance pela artista Vanessa Fredrich que explorou gestos corporais lentos e rápidos, de extensão e contração, em movimentos que se intensificavam e eram acompanhados pela música do Sigur Ros. Sua imagem era projetada na parede a sua frente, ocasionando um diálogo com seu próprio corpo, um rebatimento de imagens que se auto-construíam em tempo real.

Após finalizar a performance, as pessoas que assistiam se tornaram interatores com a obra, brincando com os seus movimentos e entre si, ocasionando um ambiente lúdico e interativo. As imagens aparecem a partir das interações entre os participantes que utilizam seus corpos e objetos pessoais (como óculos, celulares, bolsas) para produzirem coletivamente as imagens. Elas não são apenas produzidas pelos sujeitos, pelo contrário, as imagens os produzem e se manifestam como função de criação, relativamente, independente deles. "A imagem é organismo estranho, dotado de dinâmica própria, ela é exterior ao sujeito, ainda que exista nele, como uma espécie de parasita que o habita e precisa dele para se desenvolver" (KASTRUP; CARIJÓ; ALMEIDA, 2011, p. 62). Assim, produzimos imagens e as imagens nos produzem.

"Ambulações" (Figura 3) consiste em uma instalação interativa que problematiza o ato de ambular ao explorar aspectos corporais de equilíbrio/desequilíbrio, agregação/desagregação, precisão/aleatoriedade, proximidade/afastamento.

4 - Esse trabalho contou com o apoio do Prof. Dr. Juliano Esmanioto Barin e da bolsista Mônica Voss. 
Figura 2 - Andréia Machado Oliveira, Cassio Lemos, Indira Richter, Fabio Gomes de Almeida, Evaristo do Nascimento, Matheus Camargo Moreno, Tideh Azevedo, Vanessa Fredrich (Lablnter), Andressa Querubini, “... permanência do gesto..., Design+, 2017

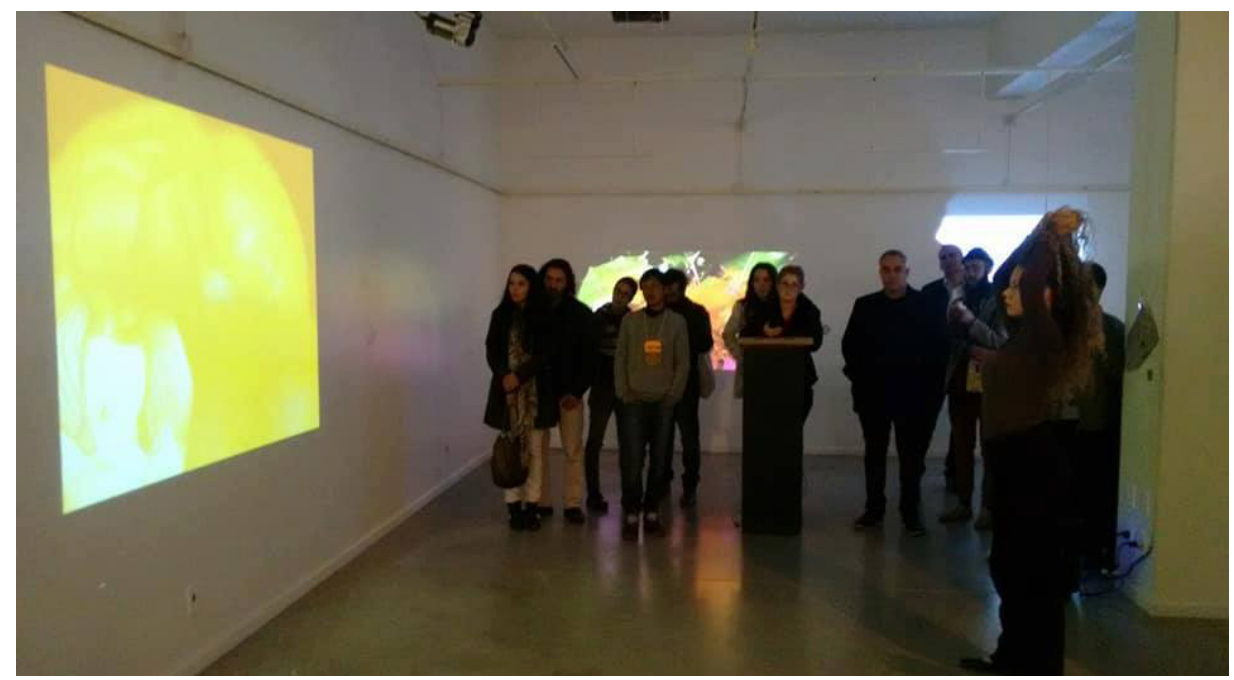

Fonte: Lablnter

Figura 3 - Andréia Machado Oliveira, Cassio Lemos, Indira Richter, Fabio Gomes de Almeida e Evaristo do Nascimento (Lablnter), "Ambulações”, IMMERSPHERE, 2017

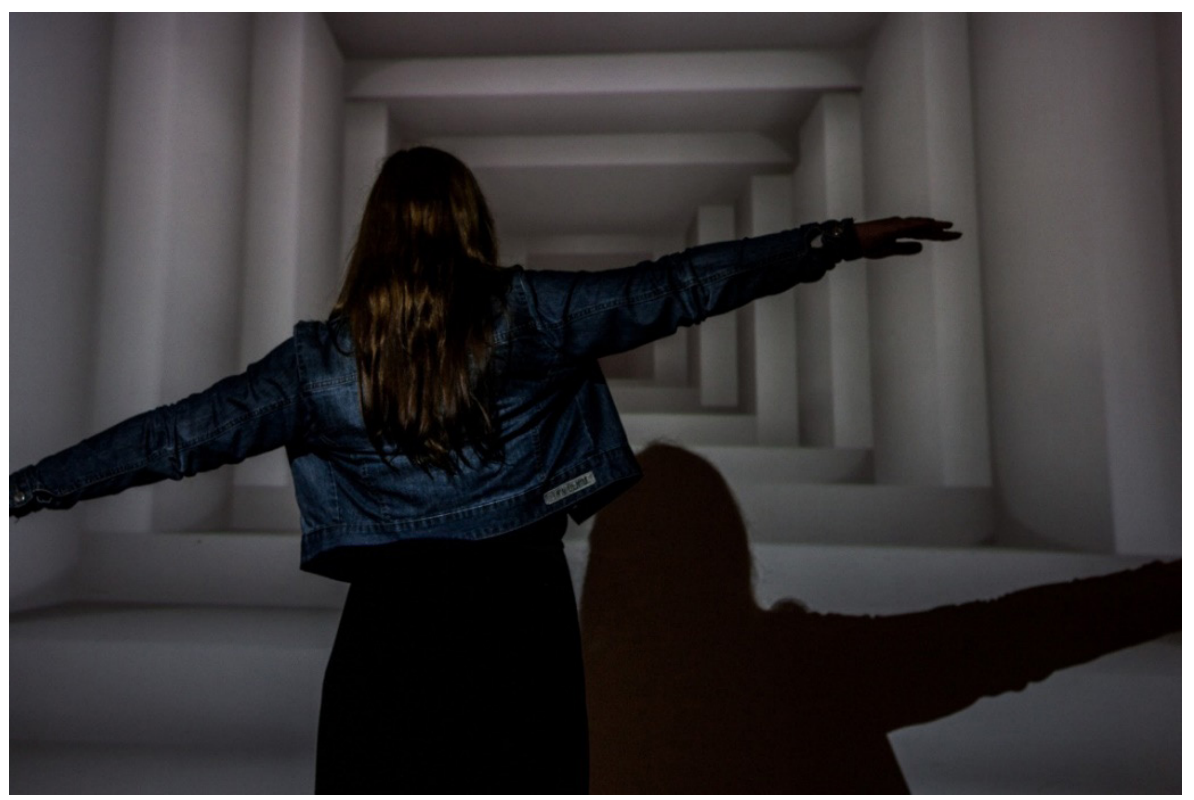

Fonte: Cássio Lemos (Lablnter)

A partir de deslocamentos entre o espaço físico e o digital, o corpo ambula e expande sua experiência perceptiva em relação ao meio no qual se encontra consigo e com os outros. De tal modo, a imagem projetada do corpo não o representa, todavia o presentifica na ação cotidiana e simples de ambular.

Ao ser exibida no evento IMMESPHERE 2017 em Brasília, os interatores alteravam a imagem de um túnel a sua frente, tendo a ilusão de estarem modificando o espaço físico com o qual interagiam. A noção de equilíbrio era perpassada pela simulação visual de um ambiente que se aproximava ou afastava de acordo com o deslocamento do interator. A interação também era instigada pela parte sonora que reagia conforme o deslocamento. O corpo respondia a uma situação de desequilíbrio não por um estímulo do espaço físico, mas por uma imagem simulacro que alterava a percepção corporal.

Portanto, nas instalações interativas "EntreMeios", "... permanência do gesto..." e "Ambulações" as imagens produzidas não buscam representar algo, mas criar situções em que o corpo experiência imageticamente através dos seus múltiplos sentidos, não ficando restrito ao visual. Tais obras nos indicam que habitamos em um mundo de imagens, bem como as 
imagens nos habitam e criam nossos mundos; nos atualizam e nos virtualizam em diferentes realidades imagéticas.

Ao pensarmos sobre a experiência da imagem nas instalações interativas produzidas pelo Lablnter, entendemos que a experiência ocorre via processos imagéticos em espaços físicos e digitais, onde o corpo produz e é produzido pelas imagens, em um ciclo que envolve a motricidade, a percepção, a imaginação e a invenção. Assim, imagem como ação torna-se experiência em instalações interativas.

\section{Referências}

COUCHOT, Edmond. A tecnologia na arte, da fotografia à realidade virtual. Porto Alegre: UFRGS, 2003.

GIANNETTI, Cláudia. O sujeito-projeto: metaperformance e endoestética. In: FILE Rio. São Paulo: FILE, 2006.

GRAU, Oliver. Arte virtual: da ilusão à imersão. São Paulo: UNESP: SENAC, 2007.

LATOUR, Bruno. Air. In: JONES, Caroline (org.). Sensorium: embodied experience, technology, and contemporary art. Cambridge: MIT, 2006.

LATOUR, Bruno. Jamais fomos modernos. São Paulo: 34, 1994.

KASTRUP, Virginia; CARIJÓ, Filipe Herkenhoff; ALMEIDA, Maria Clara de. O ciclo inventivo da imagem. Informática na Educação: teoria \& prática, Porto Alegre, v.15, n.1, jan./jun., 2012.

MASSUMI, Brian. Parables for the virtual: movement, affect, sensation. US: Duke University, 2002.

OLIVEIRA, Andreia Machado. Corpo, imagem, meio: uma proposta colaborativa em ambiente imersivo. Revista

Eletrônica MAPAD2, Bahia, v.2, n.1, 2015.

OLIVEIRA, Andréia Machado. Corpos associados: interatividade e tecnicidade nas paisagens da arte. 2010. Tese (Doutorado em Informática na Educação)-Universidade Federal do Rio Grande do Sul, Porto Alegre, dezembro de 2010.

SIMONDON, Gilbert. Imagination et invention (1965-1966). Chatou: Lês Éditions de La Transparence, 2008. 